MATEC Web of Conferences 10, 05002 (2014)

DOI: $10.1051 /$ matecconf/ 20141005002

(C) Owned by the authors, published by EDP Sciences, 2014

\title{
Structural Component Defects of Low Cost Housing: A Case Study at Taman Bandar Perdana, Sungai Petani, Kedah, Malaysia
}

\author{
M.Z. Sulieman ${ }^{1, \mathrm{a}}$, N.N. Omar ${ }^{2}$, M.A. Othuman Mydin ${ }^{3}$ \\ ${ }^{1,2,3}$ School of Housing, Building and Planning, Universiti Sains Malaysia, 11800, Penang, Malaysia
}

\begin{abstract}
Building defects are defined as building or house flaws, or design mistakes, that reduce value and cause dangerous conditions to their occupants. According to the National Building Agency, defect occurrences are caused by poor design, low quality workmanship, and quality of materials. The purpose of this paper is to identify the types of building defect that frequently occur in low cost housing. In order to do so, this paper looks into the major causes of these defects. The case study selected is at Taman Bandar Perdana, Sungai Petani, Kedah. The methodology used in this paper utilizes a literature review, interviews, and visual inspections involving both public and private sectors, in decreasing defects in buildings. The findings show that most low cost housing defects are caused by cracking, peeling paint, damp, leaking pipes, timber decay, sagging, fungi, termites, broken tiles, and electrical faults. It is widely accepted that the contributing causes of these defects include weak designs, poor workmanship, and quality of materials.
\end{abstract}

\section{Introduction}

The new economic policy for low cost housing in Malaysia was undertaken by both public and private sectors. The objective of this programme was to provide particularly low-income categories with accessibility to affordable housing. The government's commitment towards the low cost housing programme began during the First Malaysia Plan (1966-1970) and the private sector's involvement began during the Second Malaysia Plan (1971-1975); after the government realized the need and importance of the private sector's role in ensuring an adequate supply of low cost housing for the country [1]. This policy was mainly aimed at providing accessible, adequate, affordable, and quality housing for all Malaysians; particularly for those from the low-income group. However, the success of the housing policy was reduced due to reports of quality problems and defects. Building defects are defined as building or house flaws, or design mistakes that reduce value and cause dangerous conditions to their occupants. Many complaints were received from buyers involving low-cost houses [2]. These owners reported many defects, ranging from minor to major, such as the misalignment of walls and beams and leaking pipes that led to high water bills. All of these primary causes may operate singly or in combination, and produce defects indicated by changes in the composition of materials, in the construction itself, in the size, shape, or weight of materials, or simply in appearance. Therefore, this paper will study the building defects of low cost housing in Sungai Petani, Kedah, Malaysia; giving particular attention to the type of defects and their contributing causes.

Corresponding author: ${ }^{a}$ mzailan@usm.my

This is an Open Access article distributed under the terms of the Creative Commons Attribution License 2.0, which permits unrestricted use, distribution, and reproduction in any medium, provided the original work is properly cited. 


\section{Building Defects}

What are building defects? Surveyors believe that defects may be considered as a failing or shortcoming in the function, performance, statutory or user requirement of a building, and might manifest itself within the structure, fabric, services or other facilities of the affected building [2]. This includes any breach of contract affecting the quality of work, whether structural on the one hand or merely decorative on the other, and whether it is due to faulty material, workmanship, or even design, if the latter is part of the contractor's obligation [3].

Common types of building defects include structural defects resulting in cracks or collapse; defective or faulty electrical wiring and/or lighting; defective or faulty plumbing; inadequate or faulty drainage systems; inadequate or faulty ventilation, cooling or heating systems; inadequate insulation or sound proofing; and inadequate fire protection/suppression systems. Additionally, dry rot, wood rot, mould, fungus, termites, or vermin infestation may also be the result of a building defect. A building defect may also include damage caused by land movement or earth settlement.

Defects can be categorized as either structural or non-structural defects [4]. Structural defects occur in the structure of buildings, like columns, beams, walls, roofs, floors, and foundations. These defects are generally due to building settlement, deformation, serious cracking, and bowing of the building. Meanwhile, non-structural defects occur in the non-structural elements of buildings, such as the façade, floor finishes, doors, windows, rain-water down pipes, and gutters. These defects are usually caused by chemical and biological substances, significant temperature differences, condensation processes, and small cracks.

\subsection{Type of Building Defects}

Any decayed fabric should be analysed prior to carrying out repair or replacement work. This will include an analysis of defect's causes, condition and nature of existing building materials, and a survey of structural defects. The main purpose of this analysis is to make good and avoid any repetition of building problems or previous design errors. A surveyor may be specifically instructed to carry out an investigation, so that the causes of the defect can be identified and remedies allocated. Building defects can be divided into eight (8) categories, which are:

\subsubsection{Damp}

Damp is generally defined as unwanted water or moisture. Damp in a building is one of the most damaging failures that can occur. It can damage brickwork by saturating it, decay and break-up mortar joints, rot timber structures, corrode iron and steel, and damage building equipment.

\subsubsection{Cracking}

It is the nature of many construction materials to crack as they age, expand, or contract; particularly with exposure to moisture, as they get wet and dry out. Cracks commonly occur in areas such as exterior walls, interior walls, and at the corners of doors, windows, and ceilings. Referring to construction, wall cracks occur because they are overloaded or because the structure has settled or heaved. Vertical and angled cracks are usually caused by settlement or heaving. Horizontal cracks are more likely to be caused by lateral pressure [5].

\subsubsection{Peeling Paint}

Peeling paint usually occurs on building facades, mainly on plastered walls, columns, and other areas that are exposed to excessive rain and damp. Some buildings located near the sea may face a much greater risk, once the signs of peeling paint are visible on the exterior walls. 


\subsubsection{Erosion of Mortar Joints}

Basically, the main function of a mortar joint is to even out irregularities of individual blocks; whether they are stones or bricks. At the same time, they provides some adhesion between the blocks. Decayed mortar can be removed forcibly by the use of a mechanical disc or carefully raked out by using a knife or spike manually.

\subsubsection{Leaking}

Leaking is water that seeps out from behind walls, under concrete slabs and asphalt, basements, landscaping, water intrusion in roofs, irrigation systems, and radiant heat system. The consequence of leaking is damp and mould.

\subsubsection{Unstable Foundations}

Foundations are the part of a building that distributes loads from roofs, walls, and floors on to the earth below. They are structurally important to the permanence of a building. If they are insufficient, spending large sums of money on superficial restoration work is pointless.

\subsubsection{Roof Defects}

Roofs act as a weather shield, giving protection to occupants from rain and sun. There are many types of roof defects, such as broken roof tiles, damaged framing, exposed damaged felt, improper flashing, raised shadow board, and loose tiles.

\subsubsection{Termite Attacks}

Termites are small, pale to brownish black, insects that feed on wood. Timber can be weakened and in danger when attacked by insects or termites. If then exposed to water, high moisture content, and excessive loading, they can easily deteriorate. Normally, insects or termites may be present in a damp timber in wall plates or in the feet of rafters and trusses.

\section{Results, Analysis, and Discussion}

According to Figure 1, the types of low cost housing defects addressed in this study include cracking, electrical faults, paint problems, leaking pipes, drainage systems, damp, broken tiles, mould, and sagging. There aren't any issues of termite attack and timber decay. Generally, the major contributing causes of defects are weakness in design, poor workmanship, and low quality material. Furthermore, these defects are also due to a lack of awareness by occupants about the maintenance of their houses.

Table 1. Location of defects

\begin{tabular}{|c|c|c|c|c|}
\hline Location & Floor & Wall & Ceiling & Other \\
\hline Cracking & $\mathrm{X}$ & $\mathrm{X}$ & $\mathrm{X}$ & Doors \\
\hline Paint Problem & - & $\mathrm{X}$ & $\mathrm{X}$ & - \\
\hline Damp & $\mathrm{X}$ & $\mathrm{X}$ & $\mathrm{X}$ & - \\
\hline Mould and Fungi & $\mathrm{X}$ & $\mathrm{X}$ & - & . \\
\hline
\end{tabular}




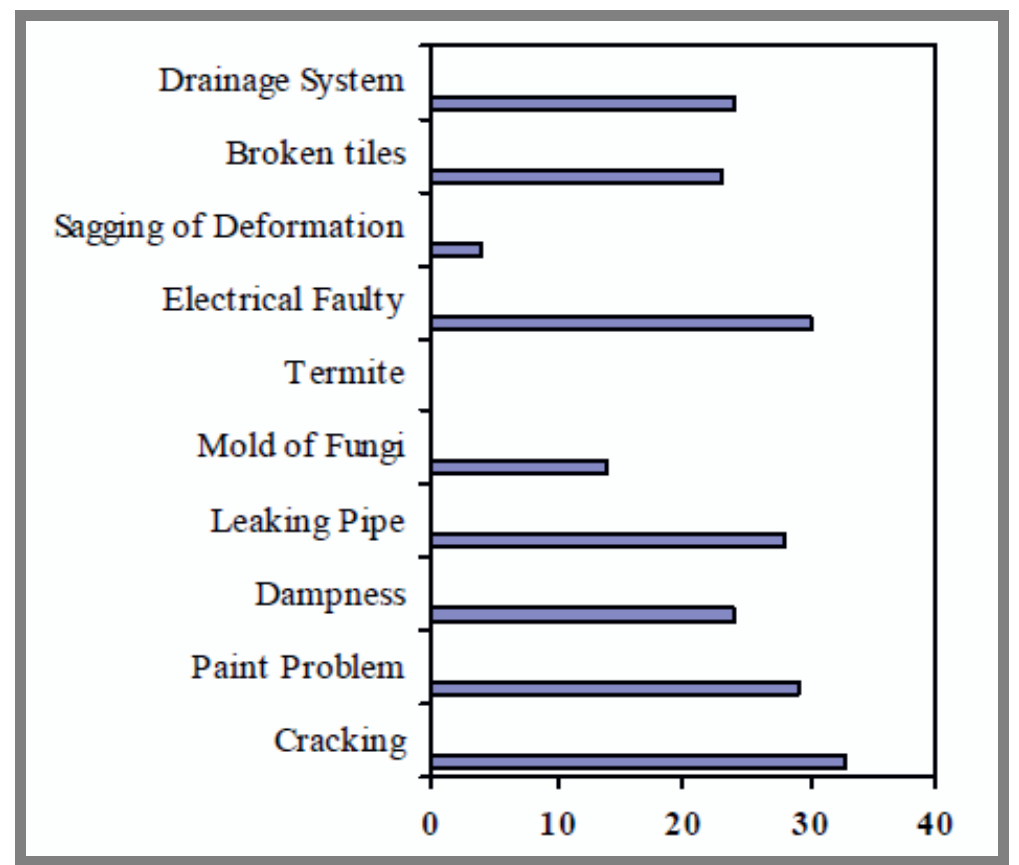

Figure 1. Types of Defect

From Figure 1, 66\% of houses had cracking problems. These cracks occurred in different areas (as shown in Table 1). The three locations that cracks occur are floors, walls, and ceilings. Based on visual inspection, the types of cracks that occur include hairline cracks and vertical cracks. Based on Figure 2, we can determine that hairline cracks on internal bedroom walls have a width of less than $1 \mathrm{~mm}$, caused by cement render.

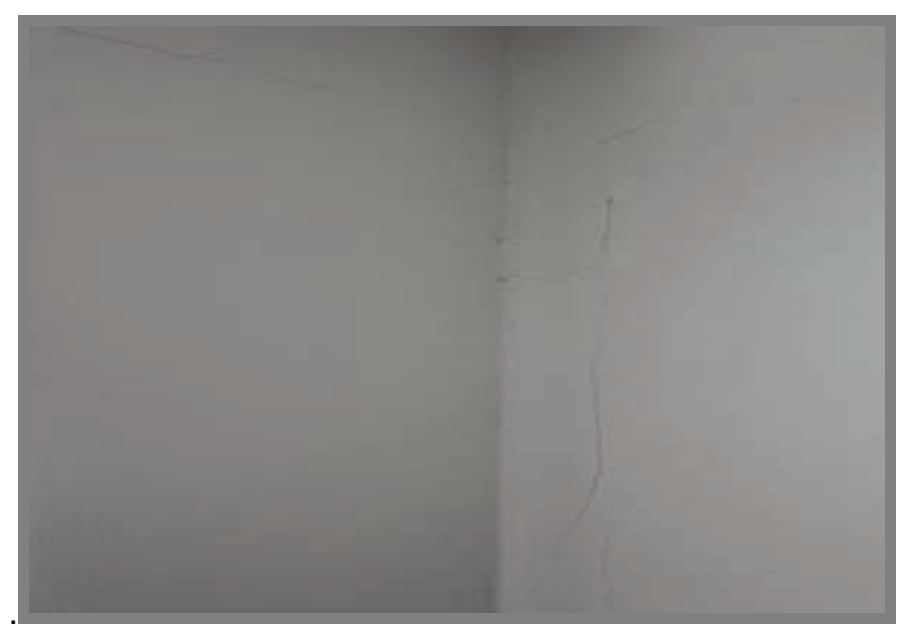

Figure 2. Hairlines cracks on internal walls

Figure 3 shows that the vertical cracks that occurred were probably caused by the failure of the foundation. This is based on the fact that signs of cracks occurred on both internal and external walls. 


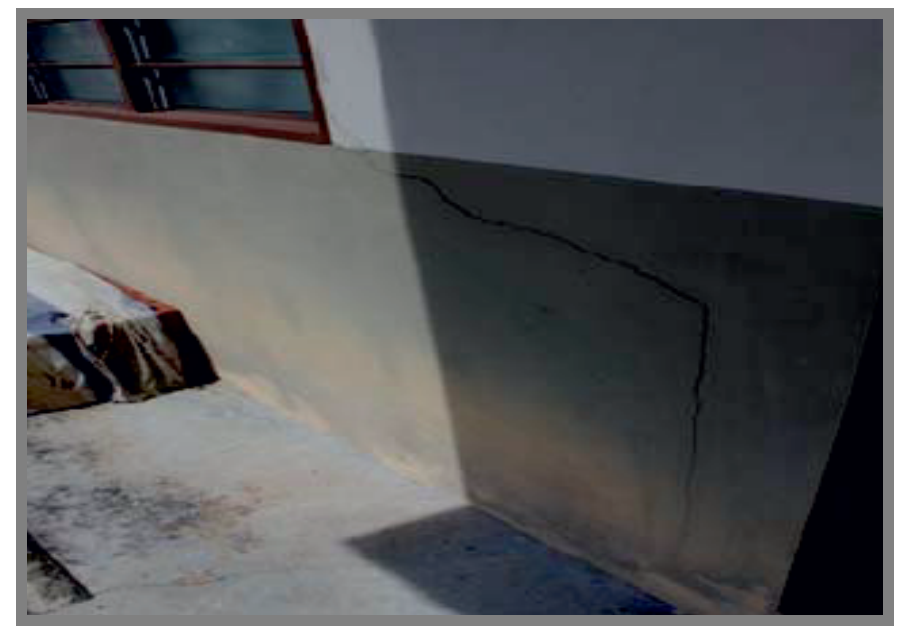

Figure 3. Vertical cracks on an external wall

In Figure 4, the cracks occurred between the wall and the ceiling. Hairlines cracks also occurred on the surface of the ceiling. The probable cause of this crack was vibration and poor workmanship. According to the data analysis from the questionnaire, about $52 \%$ of the respondents renovated their own houses. This renovation probably contributed to the causes of the cracking. Vibration, quality of workmanship, and loading change, all occurred when renovation took place. Besides that, the cause of cracking was also a probable factor of subsoil and foundation movement.

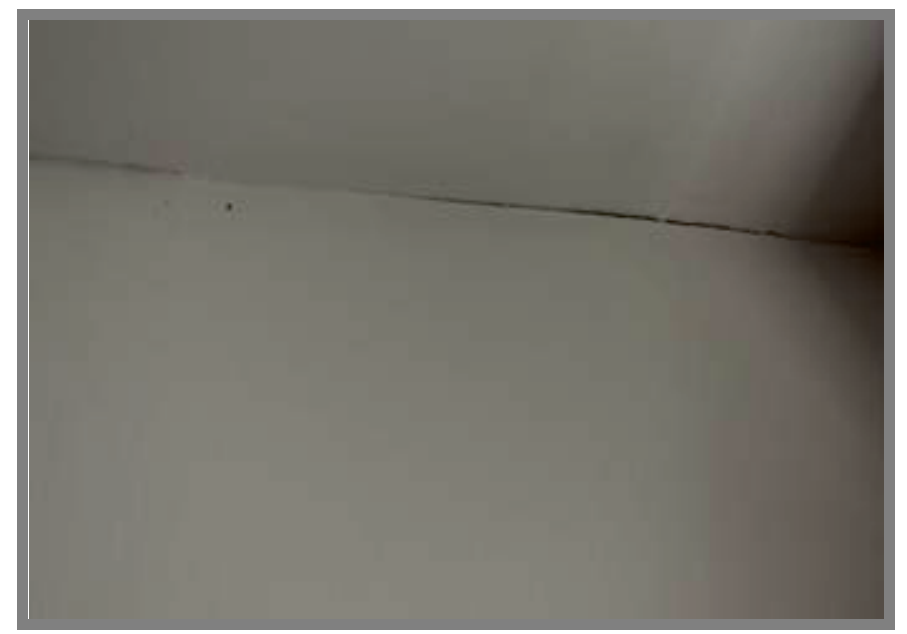

Figure 4. Cracking on ceilings

This house also had a paint problem. Approximately 58\% of houses also have a paint problem. The location of paint problems is shown in Table 1. Pain problems, such as discoloration and peeling, are presented in Figures 5 and 6. As seen, there are signs of discoloration on external walls. Paint discoloration is due to the quality of the paint used and damp on the walls. Peeling paint also occurs on front doors, because they are exposed to rain and damp. 


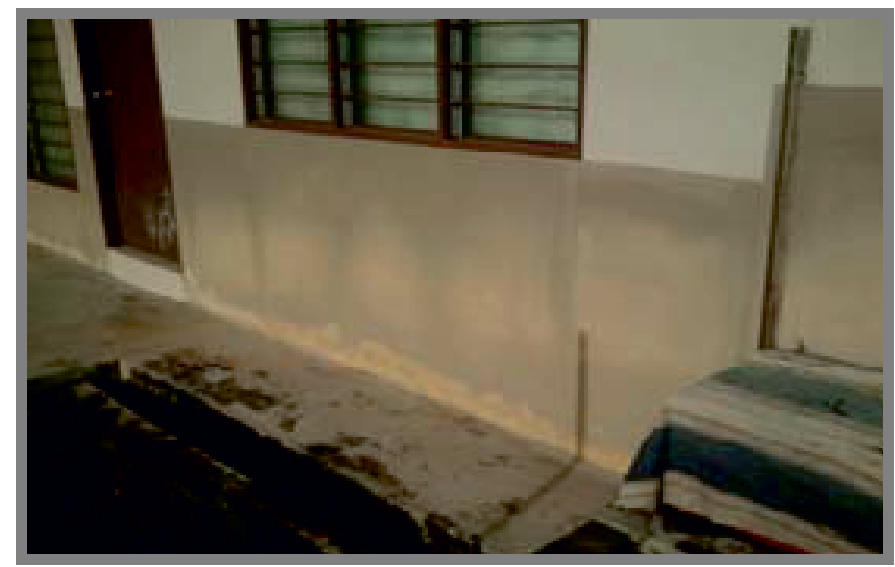

Figure 5. Discoloration on wall area

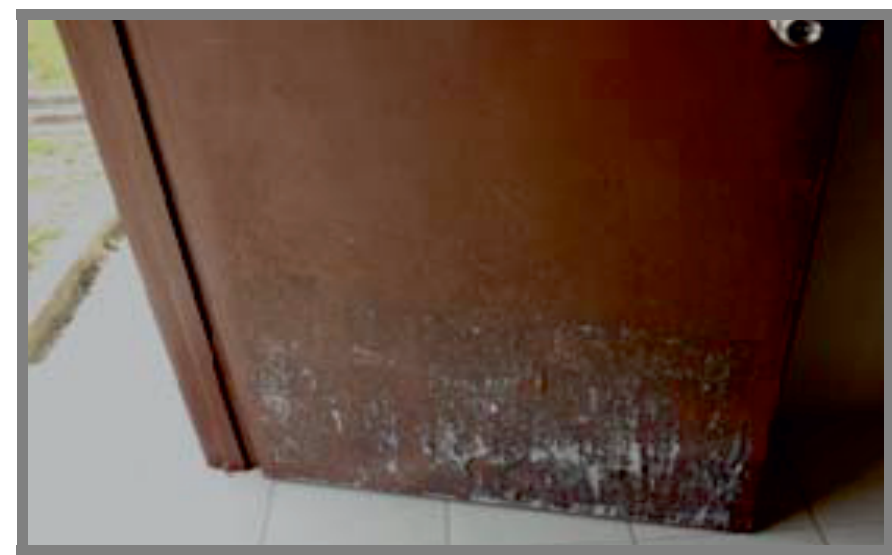

Figure 6. Peeling paint on door

However, damp is less responsible for paint problems. According to data analysis from the questionnaires, approximately $48 \%$ of respondents had damp problems. The locations of damp include floors, walls, and ceilings. Damp is caused by weakness of design. Probably the water proofing DPC on the building. From Figure 7, about $56 \%$ of houses had leaking pipes. Based on visual inspection, leaking pipes occurred on sinks, because joining pipes were not installed properly. This is due to the quality of materials and workmanship.

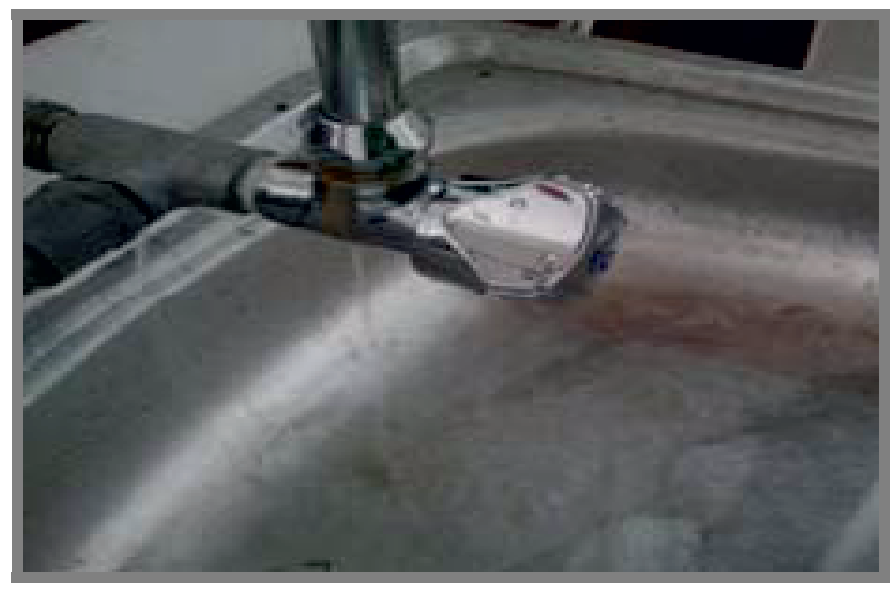

Figure 7. Leaking pipes 
Besides that, approximately $60 \%$ of houses had electrical problems. These problems included faulty electrics, such as in lamps, fans, or switches not functioning. The cause of these defects include the switches not being suited to the capacity used in the house, or not being installed properly. Figure 8 shows that broken tiles caused fewer problems. These causes were due to quality of material and workmanship.

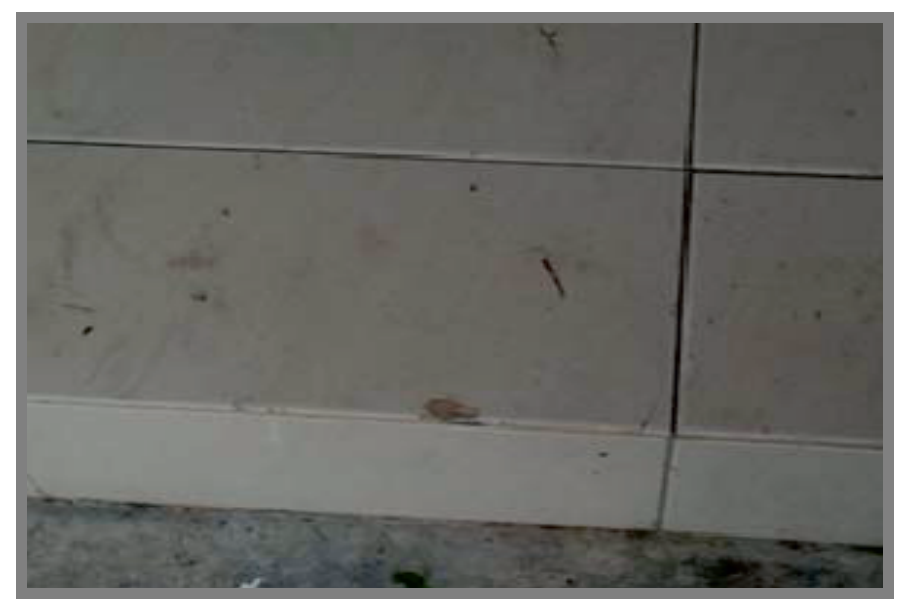

Figure 8. Broken tiles

There are many factors that contribute to the cause of defects. There are even defects that already exist in a house, before the client or customer gets the key. According to data analysis from the questionnaire, approximately $54 \%$ of respondents said that they had defects before getting their key. Figure 9 shows that major defects (before getting keys) included cracking, faulty electrics, leaking pipes, paint problems, and broken tiles. This statement was supported by an interview with the developer, who stated that the purchaser complained about defects such as cracking, leaking pipes, and paint problems.

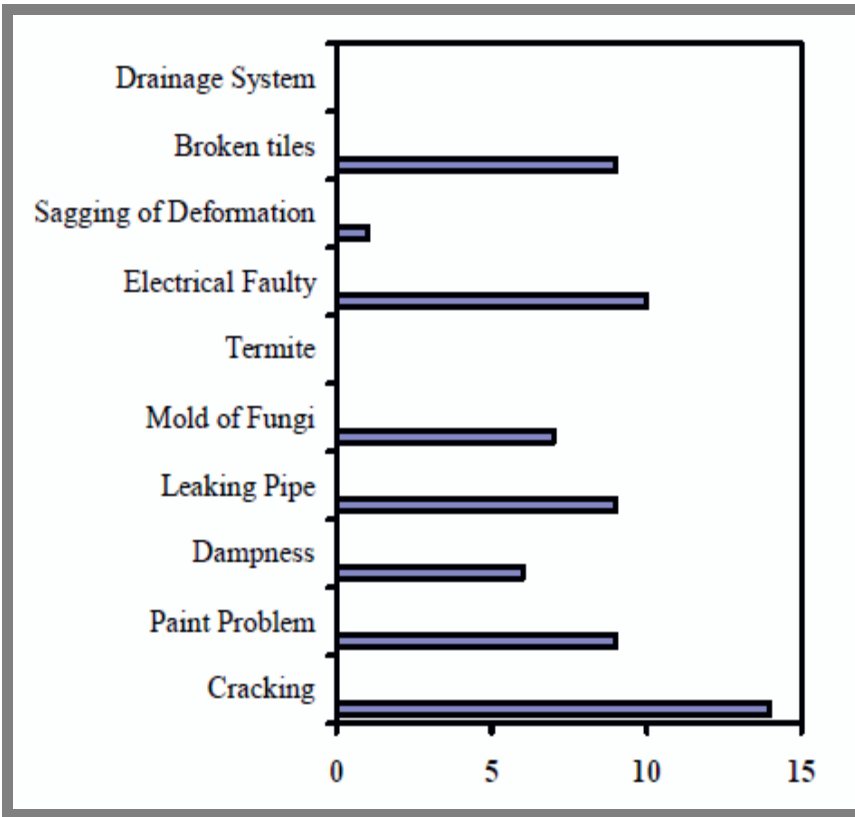

Figure 9. Types of defect before getting the key 


\section{Conclusions}

From the data collection, the findings show that the types of low cost housing defects included cracking, peeling paint, damp, leaking pipes, timber decay, sagging or deformation (roof), mould or fungi, termites, broken tiles, and faulty electrics, were identified. The majority defect occurring in low cost housing was cracking. There were no issues or defects that occurred due to termite attacks, timber decay, sagging, or deformation. The major contributing causes of defects were weakness in design, poor workmanship, and low quality of material. Furthermore, the cause of defects were also due to a lack awareness by occupants about the maintenance of their house. The consequence of faulty design affects the structure of building through vertical cracks, damp, sagging and deformation of roofs, and drainage systems. Cracks, paint problems, leaking pipes, and faulty electrics are caused by poor workmanship. Unskilled workers were probably used to construct low cost housing projects due to minimal costs. The defects that cause material problems are paint, leaking pipes, faulty electrics, and broken tiles.

\section{References}

1. S. Ghani, L.M. Lee, Low Cost Housing in Malaysia, Utusan Publication and Distribution, 1997, pp: $2-6$

2. S.W. David, Building Pathology: Introduction and Practice, John Wiley \& Son, 1999, pp: 41-55

3. A. Chamber, Hudson's Building and Engineering Contracts, Sweet \& Maxwell, 2013, pp: 21-38

4. P. Gurstien, Malaysia Architecture Heritage Survey - A Handbook Malaysia Heritage Trust, 1985, pp: $12-18$

5. J.E. Henry, Common Defects in Buildings, Great Britain, Property Services Agency, 1976 